\title{
Cardiocranial syndrome, Pfeiffer type
}

INSERM

\section{Source}

INSERM. (1999). Orphanet: an online rare disease and orphan drug data base.

Cardiocranial syndrome, Pfeiffer type. ORPHA:2872

Pfeiffer-type cardiocranial syndrome is an extremely rare disorder recognized in less than ten patients worldwide and characterized by a congenital heart defect, sagittal craniosynostosis and severe developmental delay (growth retardation and intellectual deficit). 